\title{
Analysis of Student Empowerment Role in forming Student Wellbeing
}

\author{
Yasinta Indrianti ${ }^{1}$, Sasmoko $^{2,1}$, Emny Harna Yossy ${ }^{3}$, Adi Teguh Suprapto ${ }^{4}$, \\ Hendry Hartono ${ }^{4}$
${ }^{1}$ Research Interest Group in Educational Technology, Bina Nusantara University ${ }^{2}$ Faculty of Humaniora, Bina Nusantara University ${ }^{3}$ Faculty of Information System, Bina Nusantara University ${ }^{4}$ Faculty of Management, Bina Nusantara University
Email : yasintaindrianti@gmail.com

\begin{abstract}
Creating classroom conditions to the degree of realization of student wellbeing is the most important thing for educational institutions because it is closely related to the outcome both academically and non-academically. Therefore it takes various efforts so that students can feel wellbeing. One of them is by doing student empowerment. This study aims to examine the role of student empowerment in forming student wellbeing. Research method with the survey is correlational. A technique of collecting data with Likert scale questionnaire range 1 to 5. Calibration of each instrument of student wellbeing and student empowerment with construct validity through Orthogonal Iteration approach and resulted in instrument reliability of 0.86 and 0.87 . The sample of the study were 148 students of grade 4,5 and 6 . The result showed that: Firstly, students in grades 4, 5 and 6 tend to be quite wellbeing significantly at $\alpha<0.05$. Second, that students in grades 4,5 and 6 have felt in empowerment significantly at $\alpha<0.05$. Third, there is a positive and significant influence Student Empowerment (X) with Student Wellbeing (Y) is evident in this study. Fourth, there are differences of wellbeing male students with women. So male students are more wellbeing than female students. Fifth, There is a difference in the case of the wellbeing of elementary students if differentiated education level with $\mathrm{F}$ of 3.116 is significant at $\alpha<0.05$. There is a difference in the case of elementary students who feel that they have in teacher empowerment if differentiated education level by $\mathrm{F}$ equal to 5.475 is significant at $\alpha<0.05$. It turns out that fourth-grade elementary school students feel more in teacher empowerment than 5th-grade students with a significance value of 0.012 are significant at $\alpha<0.05$. The sixth-grade students felt more in the empowerment of teachers than the 5th-grade elementary students with a significance value of 0.012 is significant at $\alpha<0.05$.
\end{abstract}

\section{Keywords: Student Empowerment; Student Well being}

\section{INTRODUCTION}

The success of education can not only be seen from academic success but also should be seen from the success of non-academic. In the non-academic realm, happiness and student well-being are one of the important indicators to note. Student wellbeing is an important approach in developing social competence, emotional competence, and student academic competence because students well-being becomes an effective foundation for students in the learning process as well as in obtaining 
positive learning outcomes [1,2]. Well, being is trying to build a person's life satisfaction [3]. Because of the strong relationship between well-being with physical health and long life so that well-being is something that is desirable and useful $[3,4]$.

Wellbeing relates to how a person evaluates himself. The evaluation includes life satisfaction, positive emotions such as fun, affection and lack of negative emotions such as sadness and anger. An individual who is willing to accept himself in a more positive way, they will appear in front of others with a certain level of confidence and optimism, which will help create a positive reaction from others and it will increase their self-esteem [5]. This evaluation is also related to the mindfulness that affects the formation of a well-being condition in a person [6]. Wellbeing can be selfacceptance, positive relationships with others, autonomy, environmental mastery, the purpose of life, and personal growth [7].

Various research studies on student well-being have been done. Research in 1995, Eder found constructions that student well-being refers to a direct experience where students feel happy in school, satisfied with the school environment because school usually deals with fear, psychological conditions, and other psychosomatic factors. Student wellbeing is individualized in that students should be able to adapt their needs and expectations to the context and demands of the school so that students can feel well in school [8].

Student well-being is a concept that has multiple aspects, namely mental, emotional, spiritual, physical and social. Each aspect works together to make individuals grow and develop in a balanced way [9]. One study found that students' perceptions become the moderating variable for student well-being because student perceptions are key to their well-being condition [8]. However, there are still many schools that have not conducted a thorough review of the student wellbeing condition since most schools focus more on students' social behavior and academic achievement [10].

In the context of education in addition to the well-being concept, the student empowerment provides a strong framework that deals with social justice for students in the learning process which is covered in three senses both socially, politically and academically. The well-being of a person also deals with the well-being of some people around them because fulfilling the needs of others can affect one's well-being beyond their needs [11]. This shows the importance of student empowerment role.

Student empowerment is believed to improve education in America. Someone is considered less fully involved with the learning process is considered as the impact of the lack of student empowerment. Student empowerment is a logical reaction for policy makers to reform school and maintain school accountability [12]. Student empowerment is defined as an effort to bring the belief that one has the ability to act effectively. In this context, the effective relationships of teachers and students need to be emphasized. The principle of mutual respect, validation, and focus on success is one form of student empowerment $[13,14]$.

Student empowerment often refers to the notion of increased student participation in the learning process [15]. Schools have the potential to create a culture of empowerment because it is able to provide quality assurance among students [16]. Empowered students are found to be more motivated to do class work so that they feel more competent, able to find the required tasks with more quality so that ultimately able to feel the impact on the learning process they have. This study finds that motivational modeling captures the main predictor of student empowerment is 
the teacher and it turns out the student's temperament does not affect student empowerment [17]. By looking at the benefits of student empowerment then this study aims to see the role of student empowerment in realizing the student wellbeing.

The research attempts to find answers to several problems, namely 1) Student Wellbeing Trends 4th, 5th and 6th-grade students ,2) Trend of Assessment of Grade 4, 5 and 6 students about empowerment of the teacher, 3) Influence of Student Empowerment to Wellbeing of Grade 4, 5 and 6 Students., 4) Differences Wellbeing Students Class 4, 5 and 6 seen from Student Sex Differences; 5) Differences Wellbeing Students Class 4, 5 and 6 seen from Student Class Differences; and 6) Student Assessment Difference on Empowerment of Teachers to Student Self is seen from Student Class Differences

\section{RESEARCH METHOD}

Research method with the survey is correlational. The sample of research is 148 students of grade 4, 5 and 6 elementary school. The research instrument consists of two questionnaires, namely questionnaire about Student Empowerment and Student Well Being. The technique of collecting data with Likert scale questionnaire range 1 to 5 .

The research instrument used to look at Student empowerment has 34 point statement with four dimension that is academic empowerment which includes develop ability, confidence and motivation to succeed; political empowerment that includes student power and student influence; social empowerment that includes dialogue between teacher and student as well as intimate exchange which includes sharing indicator [12]. While the instrument used to view the student well-being has 11 points statement. This instrument has two dimensions, namely the cognitive dimension with five indicators, namely the assessment of life, self, family, work and leisure time and affective dimension with two indicators of positive effects and negative effects [4].

Calibration of each instrument of student well-being and student empowerment with construct validity through Orthogonal Iteration approach and yielded instrument reliability of 0.86 and 0.87 .

\section{RESULT}

The results show that first, there is a positive influence of student empowerment on student well-being significantly on $\alpha<0.01$. Second, male students are more prosperous than female students with t of 2.240 significantly at $\alpha<0.05$. Third, male and female students there is no difference in the treatment of teachers that they both feel the empowerment of teachers with $t$ equal to 0.890 significantly at $\alpha<0.05$. Fourth, there is a difference in the case of the wellbeing of elementary students if differentiated education level by $\mathrm{F}$ equal to 3.116 is significant at $\alpha<0.05$. It turns out that 4th graders are more wellbeing than grade 5 and 6 students with an average score of 42.5294 with the standard deviation of 5.28107 significantly at $\alpha<0.05$. And fifth, there are differences in the case of elementary students who feel have been in teacher empowerment if differentiated education level with $\mathrm{F}$ of 5.475 is significant 
at $\alpha<0.05$. It turns out that fourth-grade elementary school students feel more in teacher empowerment than 5th-grade students with a significance value of 0.012 are significant at $\alpha<0.05$. The sixth-grade students felt more in the empowerment of teachers than the 5th-grade elementary students with a significance value of 0.012 is significant at $\alpha<0.05$.

TABLE I. RESULTS 1: STUDENT WELLBEING TRENDS 4TH, 5TH AND 6TH-GRADE STUDENTS.

\begin{tabular}{|c|c|c|c|}
\hline \multicolumn{2}{|r|}{ Descriptives } & \multirow{2}{*}{$\frac{\text { Statistic }}{40.1081}$} & \multirow{2}{*}{$\begin{array}{r}\text { Std Error } \\
.56399\end{array}$} \\
\hline Student & Mean & & \\
\hline \multicolumn{4}{|c|}{$\begin{array}{l}95 \% \text { Confidence Interval for } \\
\text { mean }\end{array}$} \\
\hline & Lower Bound & 38.9935 & \\
\hline & Upper Bound & 41.2227 & \\
\hline & $5 \%$ Trimmed Mean & 40.4850 & \\
\hline & Median & 41.0000 & \\
\hline & Variance & 47.077 & \\
\hline & Std Deviation & 6.86124 & \\
\hline & Minimum & 15.00 & \\
\hline & Maximum & 55.00 & \\
\hline & Range & 40.00 & \\
\hline & Interquartile Range & 6.00 & \\
\hline & Skewness & -1.005 & -199 \\
\hline & Kurtosis & 1.974 & .396 \\
\hline
\end{tabular}

In proving, the researcher, in this case, establishes 3 (three) categories of student wellbeing ie students: (a) not wellbeing, (b) wellbeing enough, and (c) wellbeing. Data analysis was done with a confidence interval at 5\% significance level and produced lower and upper boundary between 38.9935 until 41.2227. Based on these results, it can be concluded that students in grades 4,5 and 6 tend to be quite a wellbeing significantly at $\alpha<0.05$.

TABLE II. THE RESULT OF STUDY 2: TREND OF ASSESSMENT OF GRADE 4, 5 AND 6 STUDENTS ABOUT EMPOWERMENT OF THE TEACHER.

\begin{tabular}{|c|c|c|c|}
\hline \multicolumn{2}{|r|}{ Descriptives } & \multirow{2}{*}{$\frac{\text { Statistic }}{80.6689}$} & \multirow{2}{*}{$\frac{\text { Std Error }}{1.24220}$} \\
\hline Student & Mean & & \\
\hline \multicolumn{4}{|c|}{ Wellbeing } \\
\hline & $\begin{array}{l}95 \% \text { Confidence Interval for } \\
\text { mean }\end{array}$ & & \\
\hline & Lower Bound & 78.2140 & \\
\hline & Upper Bound & & 83.1238 \\
\hline & $5 \%$ Trimmed Mean & & 82.1021 \\
\hline & Median & & 83.0000 \\
\hline & Variance & & 228.373 \\
\hline & Std Deviation & & 12.11200 \\
\hline & Minimum & & 22.00 \\
\hline & Maximum & & 105.00 \\
\hline
\end{tabular}


TABLE II, CONT.

\begin{tabular}{|lr|}
\hline Range & 83.00 \\
Interquartile Range & 13.75 \\
Skewness & -1.741 \\
Kurtosis & 3.336 \\
\hline
\end{tabular}

To prove, the researcher, in this case, set 3 (three) categories of Student Empowerment Grade 4, 5 and 6-grade elementary students ie students: (a) not empowerment, (b) enough empowerment, and (c) disempowerment. Data analysis was done with a confidence interval at significance level 5\% and produced lower and upper boundary between 78.2140 up to 83.1238. Based on these results, it can be concluded that students in grades 4, 5 and 6 have felt in empowerment significantly at $\alpha<0.05$.

The result of research 3: There is Influence of Student Empowerment to Wellbeing of Grade 4, 5 and 6 Students.

The result of relationship analysis in the sample between Student Empowerment (X) with Student Wellbeing (Y) students of grade 4, 5 and 6 is $r_{\mathrm{y} 2}$ of 0.821 is having a positive relationship. Determination of variance that illustrates the close relationship between Student Empowerment (X) and Student Wellbeing (Y) students of grade 4, 5 and 6 is 0.672 . This means that the contribution of Student Empowerment (X) to Student Wellbeing (Y) students of grade 4, 5 and 6 is $67.2 \%$, while the condition in the population depicted by t result of 17.378 is very significant at $\alpha<0.01$. Thus the relationship between Student Empowerment (X) and Student Wellbeing (Y) students of grade 4, 5 and 6 in the population is also positive. The linear regression equation in Student Empowerment (X) sample of Student Wellbeing (Y) students of grade 4,5 and 6 is depicted by $\hat{Y}=10.037+0.373 X$. That is if students feel that the teacher often empowerment himself at least 6 times through priority program, then the new students will increase its wellbeing of $(0.373$ $\mathrm{x}$ 6) that is 2.238 times from the current condition. Based on the results of the above research, it can be concluded that the research hypothesis that reads there is a positive and significant influence Student Empowerment (X) with Student Wellbeing (Y) is evident in this study.

The result of study 4: Differences Wellbeing Students Class 4, 5 and 6 seen from Student Sex Differences.

Homogeneity test was analyzed with Levine formula produced by F 0.282 with a significance value of 0.596 is non-significant at $\alpha>0.05$. That is, variance wellbeing male students with women in equal variances assumed the position. Based on this, $t-$ student generated 2.240 with a significance value of 0.027 is significant at $\alpha<0.05$. That is, there are differences of wellbeing male students with women. So male students are more wellbeing than female students.

The result of study 5: Differences Wellbeing Students Class 4, 5 and 6 seen from Student Class Differences. 
There is a difference in the case of the wellbeing of elementary students if differentiated education level with $\mathrm{F}$ of 3.116 is significant at $\alpha<0.05$. The 4 th-grade elementary students were more than the standard deviation of 5.28107 significant at $\alpha<0.05$.

TABLE III. DATA DESCRIPTION STUDENT WELLBEING

\begin{tabular}{|c|c|c|c|c|c|c|c|c|}
\hline & & \multirow{2}{*}{ Mean } & Std & \multirow{2}{*}{$\begin{array}{l}\text { Std } \\
\text { Error }\end{array}$} & \multicolumn{2}{|c|}{ Interval for Mean } & \multirow{2}{*}{$\begin{array}{l}\text { Minimu } \\
\mathrm{m}\end{array}$} & \multirow{2}{*}{$\begin{array}{l}\text { Maximu } \\
\mathrm{m}\end{array}$} \\
\hline & & & on & & $\begin{array}{l}\text { Lower } \\
\text { Bound }\end{array}$ & $\begin{array}{l}\text { Upper } \\
\text { Bound }\end{array}$ & & \\
\hline $4^{\text {th }}$ Grade & 17 & 42.5294 & 5.28107 & 1.28085 & 39.8141 & 45.2447 & 34.00 & 52.00 \\
\hline $5^{\text {th }}$ Grade & 101 & 39.1683 & 7.43783 & .74009 & 37.7000 & 40.6366 & 15.00 & 54.00 \\
\hline $6^{\text {th }}$ Grade & 30 & 41.9000 & 4.75866 & .86881 & 40.1231 & 43.6769 & 35.00 & 55.00 \\
\hline Total & 148 & 40.1081 & 6.86124 & .56399 & 38.9935 & 41.2227 & 15.00 & 55.00 \\
\hline \multicolumn{9}{|c|}{ Table IV. Anova Analysis } \\
\hline & & Sum & of & & Mean & & \multirow[b]{2}{*}{$\mathrm{F}$} & \\
\hline \multicolumn{3}{|c|}{ Squares } & & Df & quare & & & Sig. \\
\hline Between & \multirow{4}{*}{\multicolumn{2}{|c|}{$\begin{array}{c}285.196 \\
6635.074 \\
6920.270 \\
\end{array}$}} & \multirow{4}{*}{\multicolumn{2}{|c|}{$\begin{array}{c}2 \\
145 \\
147\end{array}$}} & & & \multirow{4}{*}{3.116} & \multirow{4}{*}{.047} \\
\hline Groups & & & & & 142.5 & & & \\
\hline Within Groups & & & & & 45.7 & & & \\
\hline Total & & & & & & & & \\
\hline
\end{tabular}

There is a difference in the case of the wellbeing of elementary students if differentiated education level with $\mathrm{F}$ of 3.116 is significant at $\alpha<0.05$. The 4 th-grade elementary students were more well-being than the 5th and 6th-grade elementary students with the average score of 42.5294 with the standard deviation of 5.28107 significantly at $\alpha<0.05$.

TABLE V. DATA DESCRIPTION STUDENT EMPOWERMENT

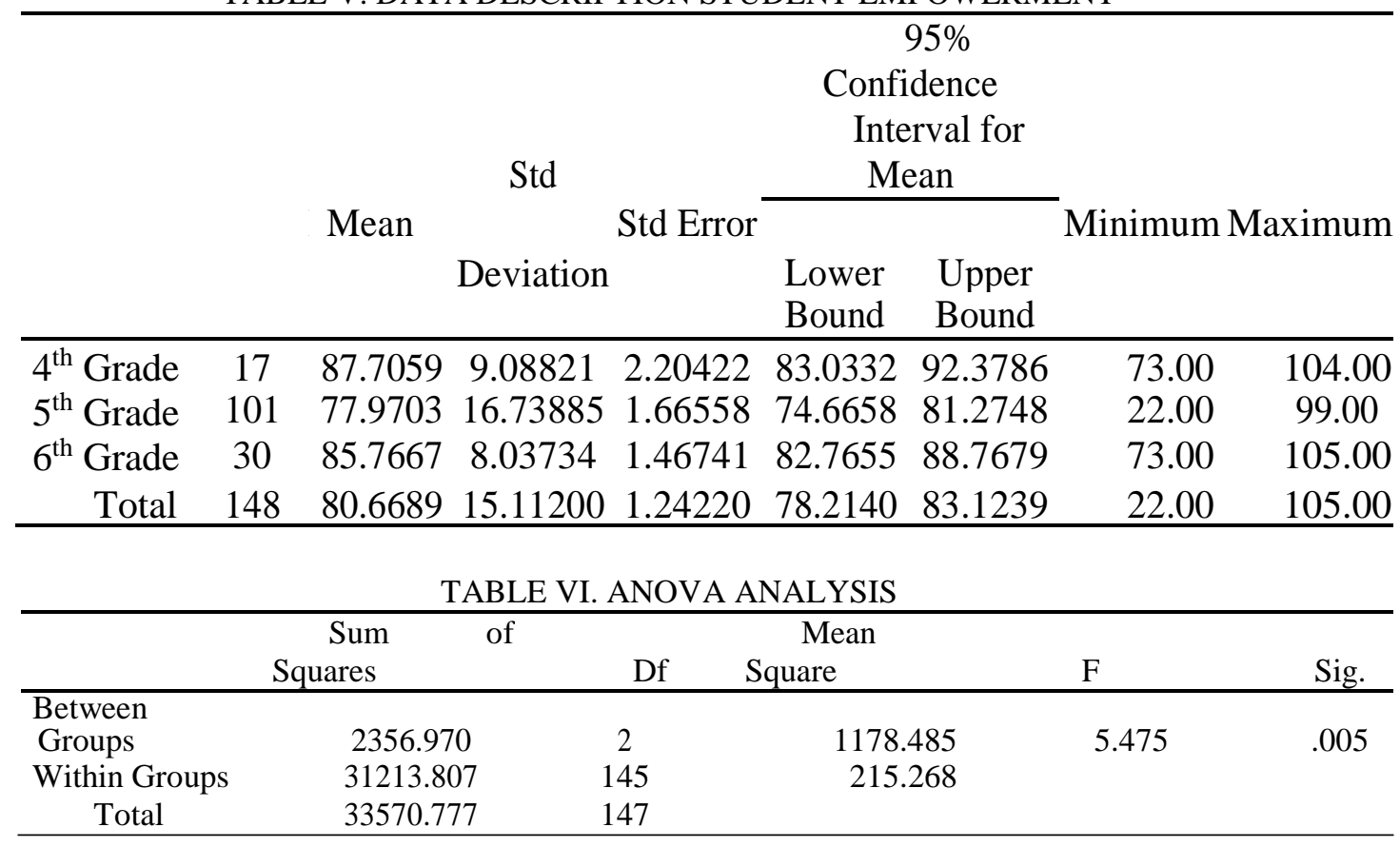


There is a difference in the case of elementary students who feel that they have in teacher empowerment if differentiated education level by $\mathrm{F}$ equal to 5.475 is significant at $\alpha<0.05$. The fourth-grade elementary school students felt more in the empowerment of teachers than the 5th-grade elementary students with a significance value of 0.012 is significant at $\alpha<0.05$. Grade 6 elementary school students felt more in teacher empowerment than grade 5 students with the significance value of 0.012 is significant at $\alpha<0.05$.

\section{DISCUSSION}

Student empowerment has been shown to influence student well-being although differences in outcomes are found to be related to gender, educational level and impacts on empowering programs that teachers have undertaken. Student well-being needs to be a focus on psychological intervention where the intervention seeks to explore positive aspects so that students show more proactive behavior than aggressive behavior [18].

In the modern era, even schools that utilize communication technology are able to develop a new culture of an online learning system. This new culture can be one of the intervention programs so students have the opportunity to empower themselves so that they can become good learners [19]. When students are empowered with a strategic approach to learning, they will be more independent and prioritize the task for themselves [20].

\section{CONCLUSION}

This study found that 1) student empowerment significantly influence student well-being; 2) male students in this study are more prosperous than female students; 3) male and female students do not feel the difference in the treatment of teachers that they both feel the empowerment of teachers; 4) there is a difference in the case of well-being of elementary students if differentiated their education level, and 5) there are differences in the case of elementary students who feel have been in teacher empowerment of differentiated education level with.

Student empowerment is believed to be able to increase relational empowerment where the opportunity is able to bridge and improve students in building networks and strengthen the competence in collaboration [21]. It is therefore important for schools not only to pay attention to academic success but also to cultivate nonacademic aspects so that empowered students will be more motivated and feel prosperous. This non-academic aspect is important to be considered and strived because in the end it will also help students in improving their overall performance. 


\section{REFERENCE}

[1] Noble, T. et al., 2008. Scoping study into approaches to student wellbeing.

[2] Spilt, J.L., Koomen, H.M.Y. \& Thijs, J.T., 2011. Teacher Wellbeing: The Importance of Teacher-Student Relationships. Educational Psychology Review, 23(4), pp.457-477.

[3] Park, N., Peterson, C. \& Seligman, M.E.P., 2004. Strengths of Character and Well - Being. Journal of Social and Clinical Psychology, 23(5), pp.603-619.

[4] Diener, E. \& Chan, M.Y., 2011. Happy People Live Longer: Subjective Well-Being Contributes to Health and Longevity. Applied Psychology: Health and Well-Being, 3(1), pp.1-43.

[5] Diener, E.D. \& Suh, E., 1997. Measuring quality of life: economic, social, and subjective indicators. Social Indicators Research, 40(1/2), pp.189-216.

[6] Reb, J.M., 2014. Mindfulness, 5(1), 36-45. , 5, pp.36-45.

[7] Ryff, C.D., 1989. Happiness is everything, or is it? Explorations on the meaning of psychological well-being. Journal of Personality \& Social Psychology, 57(6),

pp.1069-1081. Available at:

http://psycnet.apa.org/journals/psp/57/6/1069/\%5Cnhttp://search.ebscohost.com/1

ogin.aspx ?direct $=$ true $\& \mathrm{db}=$ sih $\& \mathrm{AN}=16691026 \&$ site $=$ ehost -

live\%5Cnhttp://doi.apa.org/getdoi.cfm?doi=10.1037/0022-3514.57.6.1069.

[8] Petegem, K.V.A.N. et al., 2007. Student perception as moderator for student wellbeing. , pp.447-463.

[9] Masters, G.N. \& Masters, G., 2004. Conceptualising and Researching Student Wellbeing Conceptualising and researching student wellbeing. , pp.1-6.

[10] Renshaw, T.L., Long, A.C.J. \& Cook, C.R., 2015. Assessing Adolescents Positive Psychological Functioning at School: Development and Validation of the Student Subjective Wellbeing Questionnaire., 30(4), pp.534-552.

[11] Tay, L. \& Diener, E., 2011. Needs and subjective well-being around the world. Journal of personality and social psychology, 101(2), pp.354-365.

[12] Mcquillan, P., 2015. Possibilities and Pitfalls : A Comparative Analysis of Analysis of Student Empowerment. , (March).

[13] Haynes, S.N., Richard, D.C.S. \& Kubany, E.S., 1995. Content Validity in Psychological Assessment: A Functional Approach to Concepts and Methods Introduction to Content Validity. Psychological Assessment, 7(3), pp.238-247.

[14] Burkill, S., 1997. Student empowerment through group work: A case study. Journal of Geography in Higher Education, 21(1), pp.89-94.

[15] Dimick, A.S., 2012. Student empowerment in an environmental science classroom: Toward a framework for social justice science education. Science Education, 96(6), pp.990-1012.

[16] Lundie, D., 2009. A Theory of Motivation and Ontological Enhancement: The role of disability policy in student empowerment and institutional change. Educational Philosophy and Theory, 41(5).

[17] Houser, M.L. et al., 2009. The Role of Student Characteristics and Teacher Behaviors in Students ' Learner Empowerment The Role of Student Characteristics and Teacher Behaviors in Students' Learner Empowerment. , (June 2013), pp.37-41.

[18] Chessor, D., 2008. Developing student wellbeing and resilience using a group process., 25(2).

[19] Brown, M. \& Kiriakidis, P., 2007. Student Empowerment In An Online Program. College Teaching Methods \& Styles Journal, 3(4), pp.47-54.

[20] Brinckerhoff, L.C., 2016. Making the Transition to Higher Education : Opportunities for Student Empowerment.

[21] Langhout, R. D., Collins, C., \& Ellison, E. R. (2014). Examining relational empowerment for elementary school students in a yPAR program. American journal of community psychology, 53(3-4), 369-381. 